\title{
Proteomic and functional analysis of the noncanonical poly(A) polymerase Cid14
}

\author{
CLAUDIA KELLER, KATRINA WOOLCOCK, DANIEL HESS, and MARC BÜHLER \\ Friedrich Miescher Institute for Biomedical Research, Maulbeerstrasse 66, CH-4058 Basel, Switzerland
}

\begin{abstract}
The fission yeast Cid14 protein belongs to a family of noncanonical poly(A) polymerases which have been implicated in a broad range of biological functions. Here we describe an extensive Cid14 protein-protein interaction network and its biochemical dissection. Cid14 most stably interacts with the zinc-knuckle protein Air1 to form the Cid14-Air1 complex (CAC). Providing a link to ribosomal RNA processing, Cid14 sediments with $60 \mathrm{~S}$ ribosomal subunits and copurifies with $60 \mathrm{~S}$ assembly factors. In contrast, no physical link to chromatin has been identified, although gene expression profiling revealed that efficient silencing of a few heterochromatic genes depends on Cid14 and/or Air1.
\end{abstract}

Keywords: TRAMP; CAC; heterochromatin silencing; ribosome biogenesis; poly(A) polymerase; Cid14

\section{INTRODUCTION}

Proper gene expression requires polyadenylation of most eukaryotic mRNA 3' ends by the canonical poly(A) polymerase (PAP), which has been shown to be important for RNA export, translation, and RNA stabilization. Besides the canonical PAP, eukaryotic cells possess noncanonical PAPs, which have been implicated in a broad range of biological processes and are conserved from yeast to humans. The fission yeast Schizosaccharomyces pombe encodes six noncanonical PAPs: Cid1, Cid11, Cid12, Cid13, Cid14, and Cid16 (Stevenson and Norbury 2006). Although initially classified as noncanonical PAPs, some of these enzymes have been demonstrated to add U residues (Kwak and Wickens 2007; Rissland et al. 2007). Cid14 is a nuclear enzyme which preferentially adds purines to RNA substrates in vitro, functions in ribosomal RNA (rRNA) processing and heterochromatic gene silencing, and is required for faithful chromosome segregation, proper siRNA generation by the RNA interference (RNAi) pathway, and maintenance of genomic integrity of the ribosomal DNA (rDNA) locus (Win et al. 2006; Bühler et al. 2007, 2008; Wang et al. 2008; Bühler 2009).

Cid14 is a functional ortholog of the two noncanonical PAPs, Trf4p/5p, found in the distantly related budding yeast Saccharomyces cerevisiae (Win et al. 2006). Both Trf4p and

Reprint requests to: Marc Bühler, Friedrich Miescher Institute for Biomedical Research, Maulbeerstrasse 66, CH-4058 Basel, Switzerland; e-mail: marc.buehler@fmi.ch; fax: 41-61-697-39-76.

Article published online ahead of print. Article and publication date are at http://www.rnajournal.org/cgi/doi/10.1261/rna.2053710.
Trf5p are found together with predicted zinc-knuckle proteins Air1p/2p and the helicase Mtr4p in complexes termed TRAMP4 (Trf4p-Air1p/2p-Mtr4p; LaCava et al. 2005; Vanacova et al. 2005; Wyers et al. 2005) and TRAMP5 (Trf5p-Air1p-Mtr4p; Houseley and Tollervey 2006). The TRAMP complexes are considered to be cofactors of the yeast nuclear exosome that functions to process or degrade RNAs (Mitchell et al. 1997; Mitchell and Tollervey 2000).

Here we report the existence of a single TRAMP-like complex in S. pombe, consisting of Mtr4, Cid14, and Air1. Whereas Air1 and Cid14 form a stable complex, the association with Mtr4 is weak and occurs only in the presence of both Cid14 and Air1. Moreover, Cid14 sediments with 60S ribosomal subunits and copurifies with $60 \mathrm{~S}$ assembly factors, providing a link to its role in ribosomal RNA processing. Previously we have shown that efficient silencing of transgene insertions at heterochromatic loci depends on Cid14 (Bühler et al. 2007). Here we demonstrate that silencing of a few endogenous heterochromatic genes depends on Cid14. In contrast to the factors implicated in ribosome biogenesis, no components have been identified that would link Cid14 to chromatin. Therefore, we propose that Cid14 functions off chromatin to control gene expression.

\section{RESULTS AND DISCUSSION}

\section{Cid14 stably associates with the zinc-knuckle protein Air1}

Previously, we have shown that Cid14 copurifies with a large number of proteins, including ribosomal proteins 
(RPs) and two proteins that are homologs of the budding yeast Mtr4p and Air1p/2p (Bühler et al. 2007). To better characterize this protein-protein interaction network, we revisited affinity chromatography under various conditions. We started our analysis by tandem affinity purifications of fully functional C-terminally TAP-tagged Cid14 (Cid14-TAP; Bühler et al. 2007) at different salt concentrations followed by analysis of the purification by SDS polyacrylamide gel electrophoresis and mass spectrometry. LC-MS/MS analysis of tryptic digests of protein mixtures of Cid14-TAP and control purifications revealed that Cid14 copurifies specifically with Air1 (SPBP35G2.08c), Mtr4 (SPAC6F12.16c), and a large number of RPs at $150 \mathrm{mM}$ $\mathrm{NaCl}$ (Fig. 1A,D). Association with Mtr4 and RPs was gradually lost with increasing $\mathrm{NaCl}$ concentrations or upon treatment with RNase I (Fig. 1B,D). The only detectable
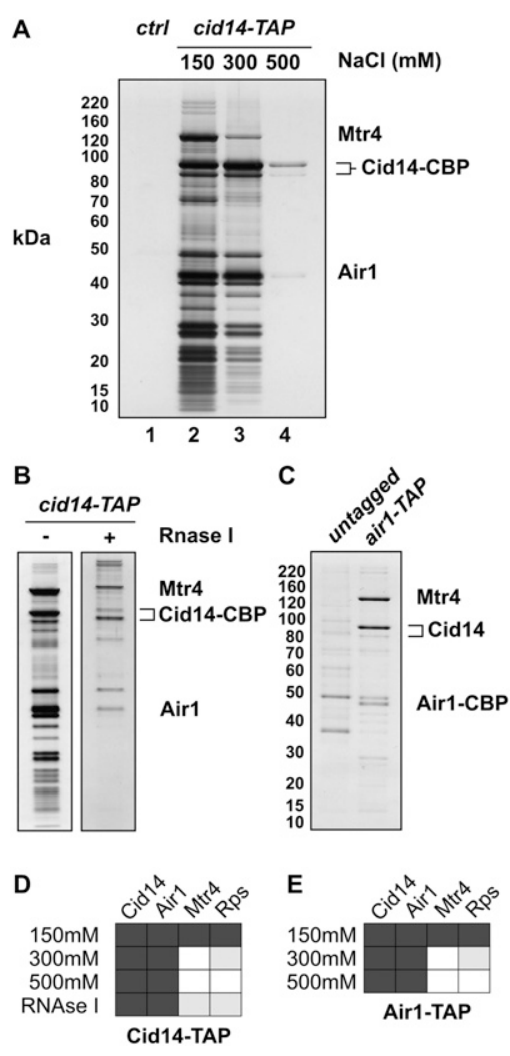

FIGURE 1. Cid14 interacts with Air1, Mtr4, and ribosomal proteins. (A) Silver-stained gel showing Cid14-TAP purifications under increasing salt conditions. The positions of Mtr4 (126 kDa), Cid14-CBP $(83 \mathrm{kDa})$, a Cid14 degradation product, Air1 $(35 \mathrm{kDa})$, and a molecular weight marker (left) are indicated. CBP, calmodulin binding peptide. (B) Silver-stained gel showing an RNase-treated Cid14-TAP purification. Five-hundred units of RNase I were added after the TEVcleavage reaction for $1 \mathrm{~h}$ at RT. $(C)$ Silver-stained gel showing an Air1TAP purification $(150 \mathrm{mM} \mathrm{NaCl})$. $(D, E)$ Table summarizing the LCMS/MS results of the TAP purifications under various conditions (see also Supplemental Table S1). TAP elutions were TCA-precipitated and processed for LC-MS/MS analysis. RPs, ribosomal proteins. Black, gray, and white boxes indicate peptides that are, respectively, of high abundance, medium abundance, or absent in LC-MS/MS. interaction preserved at $500 \mathrm{mM} \mathrm{NaCl}$ was with Air1 (Fig. 1A,D; Supplemental Table S1). Thus, Cid14 and Air1 form a stable complex, independently of Mtr4. We refer to this complex as Cid14-Air1 Complex (CAC). Similarly, Trf4p has been shown to stably associate with either Airlp or Air $2 \mathrm{p}$ in $S$. cerevisiae. Interestingly, this interaction is necessary for PAP activity (Vanacova et al. 2005; Wyers et al. 2005). In contrast, Cid14 shows PAP activity independently of Air1 (Bühler et al. 2007).

\section{Mtr4, Cid14, and Air1 form a TRAMP-like complex in $S$. pombe}

At low salt concentrations, Cid14 reproducibly copurified with Mtr4 and Airl, suggesting that a TRAMP-like complex also exists in S. pombe. To verify this, we constructed a strain expressing a C-terminally TAP-tagged Air1 protein (Air1-TAP). Affinity purification followed by mass spectrometry identified Cid14 and Mtr4 as Air1-interacting proteins, as well as RPs (Fig. 1C). Mtr4 and RP association was also sensitive to high salt concentrations (Fig. 1E and data not shown). Similarly, $500 \mathrm{mM} \mathrm{NaCl}$ washes have been demonstrated to dissociate Mtr4p from Trf4p, Trf5p, and Air2p in S. cerevisiae (LaCava et al. 2005). RNAse treatment of the Cid14-TAP complex bound to IgG beads prior to release by TEV cleavage did not abolish the recovery of Airl and Mtr4 (Fig. 1B), whereas binding of RPs, in particular 40S ribosomal proteins, was reduced (Fig. 1B,D; Supplemental Table S1). This makes it unlikely that Mtr4, Cid14, and Air1 interact via substrate RNAs. Based on these results, we conclude that a TRAMP-like complex does exist in $S$. pombe.

In S. cerevisiae, $\operatorname{Trf} 4 \mathrm{p}$ can either interact with Airlp or Air2p, suggesting the existence of two TRAMP complexes containing either Air1p or Air2p associated with Trf4p and Mtr4p (Wyers et al. 2005). Although S. pombe encodes for more than one Airlp/2p homolog, we consistently identified Air1 by LC-MS/MS from Cid14-TAP purifications (Supplemental Table S1). To rule out that a related zincknuckle protein could substitute in the absence of Air1, we purified Cid14-TAP expressed in airls cells. These purifications did not reveal any other Air1 homologs associating with Cid14 (Fig. 2C,E; Supplemental Table S1). Thus, Air1 is the sole zinc-knuckle protein interacting with Cid14. Furthermore, we purified Air1-TAP from cid14A cells and found no other Cid14 homologs copurifying with Air1 (Fig. 2D). In conclusion, the association of CAC with Mtr4 represents the only TRAMP-like complex in S. pombe. Importantly, Cid14-TAP purifications from air1s cells revealed that Mtr4 no longer interacts with Cid14 in the absence of Air1 (Fig. 2C,E). This may suggest that Air1 mediates the interaction with Mtr4. However, Mtr4 was also lost when we purified Air1-TAP from cid14A cells (Fig. $2 \mathrm{D}, \mathrm{E})$. Therefore, an intact CAC complex is required for TRAMP formation in fission yeast. 
A

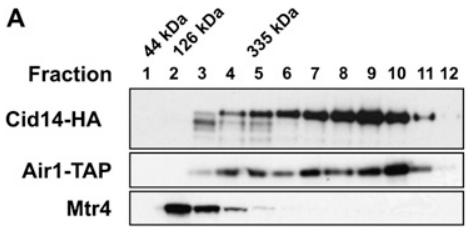

B

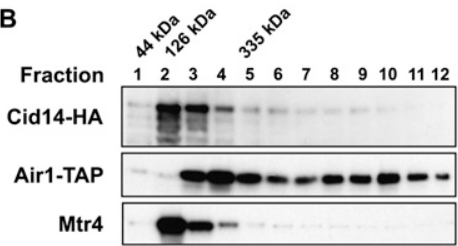

$\mathbf{F}$

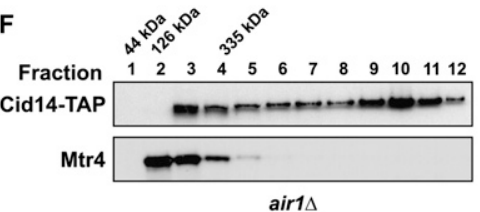



G

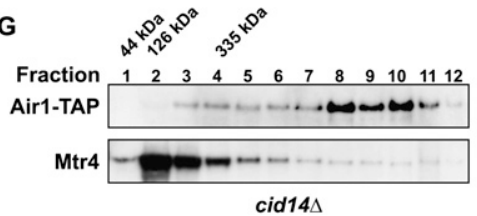

FIGURE 2. Cid14 resides in high and low molecular weight complexes. (A) Sucrose gradient fractionation under low salt conditions $(150 \mathrm{mM} \mathrm{NaCl})$. Individual fractions from sucrose density gradients were analyzed by Western blotting with antibodies recognizing Cid14-HA, Air1-TAP, or Mtr4. (B) Sucrose gradient fractionation under high salt conditions $(500 \mathrm{mM}$ $\mathrm{NaCl}$ ). The analysis was performed as in $A$. (C) Silver-stained gel showing Cid14-TAP purifications performed with wild-type and airls cells. (D) Silver-stained gel showing Air1TAP purifications performed with wild-type and cid14A cells. $(C, D)$ Salt concentration was $150 \mathrm{mM}$. (E) Table summarizing LC-MS/MS results of TAP purifications shown in $C$ and $D$. Black, gray, and white boxes indicate peptides that are of high abundance, medium abundance, and absent in LC-MS/MS, respectively. $(F, G) S$. pombe lysates from cid14-TAP airld and air1$T A P$ cid $14 \Delta$ cells were separated by sucrose density gradient centrifugation. $(A, B, F, G) S$. pombe total cell lysates were loaded onto an $18 \%-54 \%$ sucrose gradient and protein complexes were separated by ultracentrifugation at $39,000 \mathrm{rpm}$ for $18 \mathrm{~h}$.

\section{Cid14 associates with 605 ribosomal subunits and assembly factors}

The results described above show that Cid14 resides in at least two biochemically distinct protein complexes, CAC and TRAMP. Importantly, Cid14 has previously been shown by gel filtration experiments to be part of a complex much larger than CAC and TRAMP (Win et al. 2006). Consistently, sucrose gradient fractionation indicated that Cid14 is part of both low and high molecular weight protein assemblies (Fig. 2A). We observed the same for Air1, but not Mtr4. Mtr4 sedimented mainly in fraction 2, which represents its own molecular weight of $\sim 126 \mathrm{kDa}$ (Fig. 2A,B). Thus, Mtr4 seems unlikely to be a stable component of any larger protein assemblies. Furthermore, only a small fraction of the Mtr4 population seems to be associated with CAC to form spTRAMP, similar to what has also been described for Mtr4p in S. cerevisiae (LaCava et al. 2005).

The high number of copurifying RPs and the sedimentation of Cid14 in high molecular weight fractions is indicative of an association with ribosomes. Interestingly, Cid14 has been reported to be involved in 25S rRNA processing (Win et al. 2006), suggesting that Cid14 might interact with ribosomal proteins during assembly of the large ribosomal subunit. Therefore, we performed ribosome fractionation on sucrose gradients ranging from $10 \%$ to $50 \%$ by centrifugation for $15 \mathrm{~h}$ followed by Western blotting to detect Cid14-TAP. Consistent with its known role in 25S rRNA processing, Cid14 was mainly detected in fractions representing the $60 \mathrm{~S}$ large ribosomal subunit (Fig. 3A). Importantly, five proteins known to be involved in $60 \mathrm{~S}$ biogenesis could be identified by LCMS/MS after reducing the complexity of our Cid14-TAP purification by SDSPAGE separation and performing the tryptic digest on individual gel bands (Fig. 3B). Thus, we conclude that the higher molecular weight Cid14 complex represents a $60 \mathrm{~S}$ ribosomal subunit assembly protein-protein interaction network.

\section{Silencing of a few endogenous heterochromatic genes depends on Cid14}

Previously we have shown that efficient silencing of transgene insertions at heterochromatic loci depends on Cid14 (Buhler et al. 2007). However, it remained to be tested to what extent Cid14 also functions in heterochromatic silencing of endogenous genes and whether this depends on an intact TRAMP complex. Therefore, we hybridized total RNA isolated from wildtype, cid14A, and air $1 \Delta$ cells to affymetrix tiling arrays. Taking the average of two biological replicates and using a cutoff of 1.5-fold, 149 and 323 genes were shown to be up-regulated in cid14 $\Delta$ and air $1 \Delta$ cells, respectively, while 73 and 86 were down-regulated (Fig. 4A,B). Interestingly,

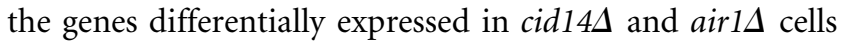
overlapped only partially, suggesting that Air1 and Cid14 can also function outside the CAC or TRAMP complexes (Fig. 4A,D). Consistent with this, we noticed that both Cid14 and Airl associated with high molecular weight protein assemblies independently of each other (Fig. 2F,G).

Comparing the expression in cid14A to previously published $\mathrm{H} 3 \mathrm{~K} 9 \mathrm{me} 2$ and $\mathrm{HP} 1^{\text {Swi6 }}$ ChIP-on-chip data (Cam et al. 2005) revealed that only a small set of heterochromatic genes was up-regulated in cid14D (Fig. $4 \mathrm{E}$; Supplemental Table S2). The majority of these are subtelomeric genes, as previously described (Wang et al. 2008). Importantly, not all of these heterochromatic genes were up-regulated in airl $\Delta$ cells, suggesting that an intact CAC and/or TRAMP complex is not always necessary to 
A

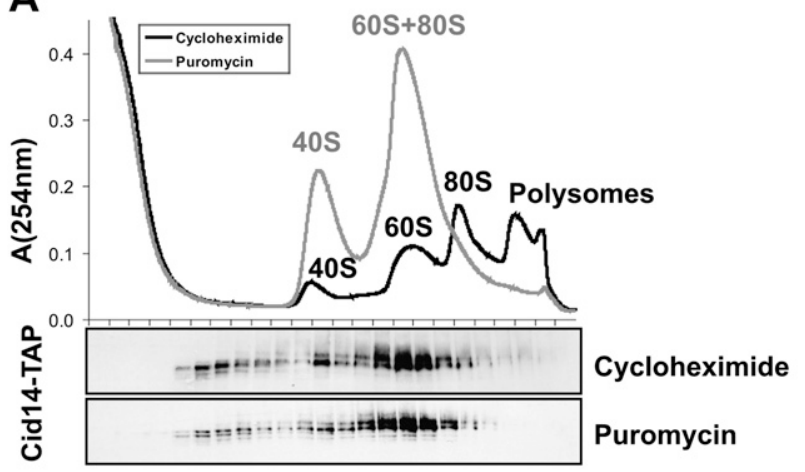

Fractions 1-24

B

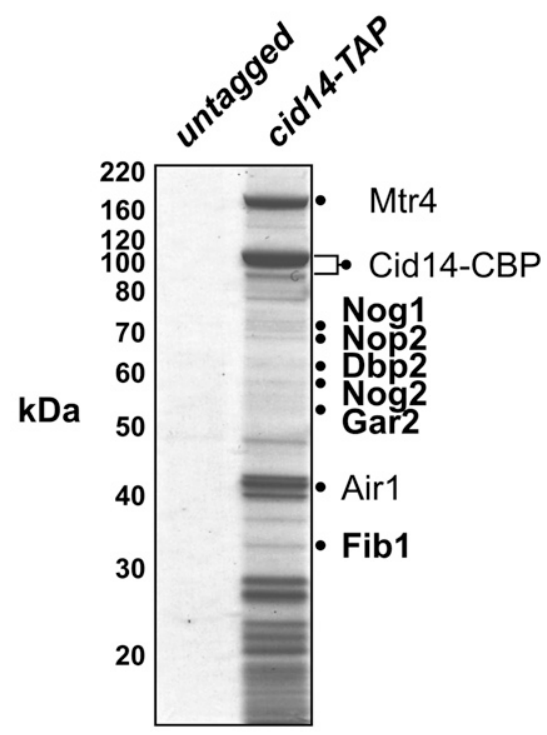

\begin{tabular}{llcccl} 
Protein & GeneDB & kDa & $\%$ & $\#$ & function \\
\hline Nop2 & SPBP8B7.20c & 68.9 & 7 & 3 & 60 S biogenesis \\
Nog1 & SPBC651.01c & 72.8 & 10 & 5 & 60 biogenesis \\
Gar2 & SPAC140.02 & 53 & 12 & 4 & $40 S$ \\
Dbp2 & SPBP8B7.16c & 61.5 & 4 & 2 & $60 S$ \\
"Nog2" & SPAC6F6.03c & 59.9 & 4 & 2 & $60 S$ \\
Fib1 & SPBC2D10.10c & 32 & 12 & 3 & $40 S / 60 S$
\end{tabular}

FIGURE 3. Cid14 associates with $60 \mathrm{~S}$ ribosomal subunits and $60 \mathrm{~S}$ ribosome assembly factors. (A) Sedimentation behavior of Cid14-TAP in $10 \%-50 \%$ ribosome sucrose gradients. UV profile (OD at $254 \mathrm{~nm}$ ) with ribosomal subunits, mono- and polysomes is indicated. Samples were treated with cycloheximide to stabilize or puromycin to disrupt polysomes. Twenty-four fractions were collected and analyzed by Western blotting against Cid14-TAP. (B) Cid14-TAP and control purifications from $20 \mathrm{~g}$ of cells were separated by SDS-PAGE followed by Coomassie-staining. Bands were cut out and LC-MS/MS analysis was performed on in-gel processed samples. Positions of the bands and the corresponding proteins indentified by LC-MS/MS are indicated. \%, percent sequence coverage; \# number of unique peptides.

silence heterochromatin (Supplemental Table S2). Although future work on Air1 and its RNA binding properties will be required to rule out alternative functions, we speculate that Airl functions as an RNA adaptor to support the association of Cid14 with its substrate. Depending on yet to be determined characteristics of a Cid14 substrate, Air1 might be more or less important for this.

\section{Conclusions}

Our findings that Cid14 associates with $60 \mathrm{~S}$ ribosomal subunits and with proteins known to be involved in $60 \mathrm{~S}$ biogenesis strongly suggest that Cid14 is directly involved in the assembly of pre-ribosomes. This is further supported

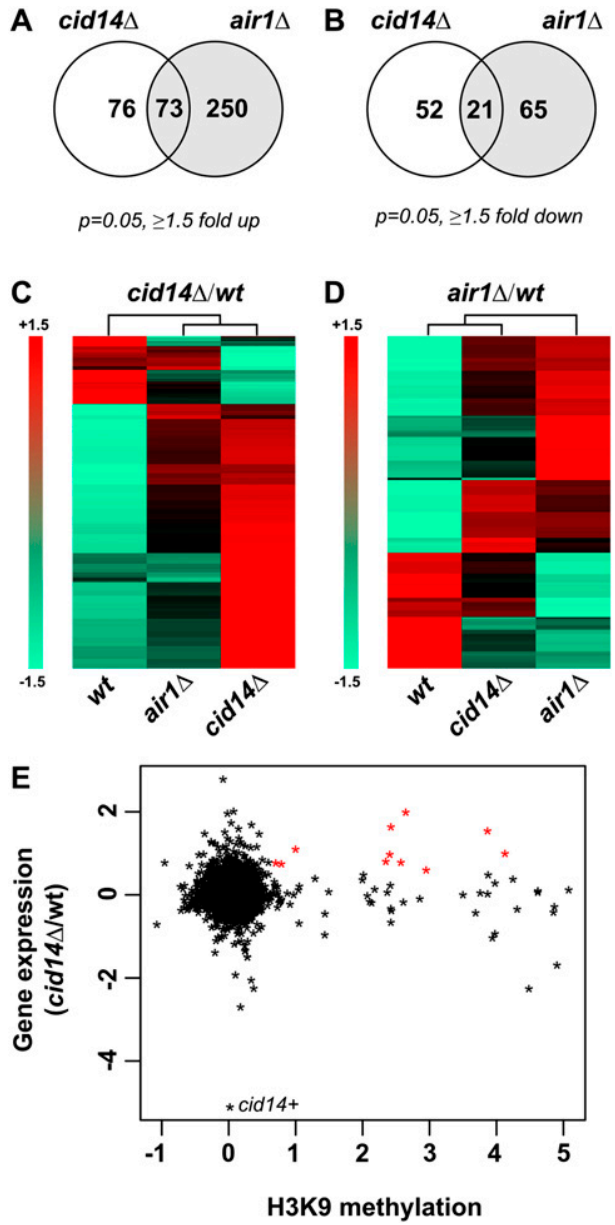

FIGURE 4. Differential gene expression in cid14t and airls cells. $(A, B)$ Venn diagrams showing the number of genes up- or down-

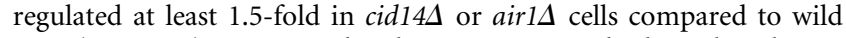
type $(P=0.05)$ on $S$. pombe tiling arrays. Two biological replicates were analyzed. $(C)$ Heatmap displaying the genes which were up- or down-regulated at least 1.5 -fold $(P=0.05)$ in cid $14 \Delta$ cells compared to wild type on $S$. pombe tiling arrays. $(D)$ Heatmap displaying the genes which were up- or down-regulated at least 1.5-fold $(P=0.05)$ in airl $\Delta$ cells compared to wild type on $S$. pombe tiling arrays. $(C, D)$ Artificially scaled expression values are shown for the strains indicated $(-1.5$ is set for the gene with the lowest expression and +1.5 is set for the gene with the highest expression). (E) Comparison of genes upregulated in cid144 cells to previously published H3K9me2 ChIP-onchip data (Cam et al. 2005). Asterisks in red indicate those genes that have a value $>0.6$ (log scale) in both the expression and ChIP experiments (listed in Supplemental Table S2). 
by the nucleolar localization of Cid14 and its role in rRNA metabolism (Win et al. 2006; C Keller and M Bühler, unpubl.). Therefore, we propose that Cid14 is physically linked to ribosome biogenesis. Cid14 also functions in eliminating a variety of RNAs, amongst them transcripts originating from subtelomeric heterochromatin (this study; Bühler et al. 2007; Wang et al. 2008). In contrast to RPs and ribosome assembly factors, we were not able to identify proteins which could link Cid14 to heterochromatin physically. Therefore, we favor a model in which Cid14 recognizes and eliminates heterochromatic RNAs off chromatin. Finally, our biochemical and functional data suggest that Cid14 may at least partially function outside of an intact TRAMP complex. Future work will be required to elucidate substrate characteristics and requirements for Cid14 and/or the TRAMP complex.

\section{MATERIALS AND METHODS}

\section{Strains and plasmids}

Fission yeast strains used in this study are described in Supplemental Table S3 and were grown at $30^{\circ} \mathrm{C}$ in YES (Yeast Extract with Supplements). All strains were constructed following a standard PCR-based protocol (Bahler et al. 1998).

\section{Tandem affinity purification}

A 2-L culture of TAP-tagged $S$. pombe cells $(\mathrm{OD}$ at $600 \mathrm{~nm} \approx 2$ ) was pelleted, washed once in ice-cold $\mathrm{PBS}$, resuspended in $1 / 4$ pellet volume of lysis buffer $\left(6 \mathrm{mM} \mathrm{Na}_{2} \mathrm{HPO}_{4}, 4 \mathrm{mM} \mathrm{NaH}\right.$ $\mathrm{PO}_{4} \bullet \mathrm{H}_{2} \mathrm{O}, 1 \% \mathrm{NP}-40,150 \mathrm{mM} \mathrm{NaCl}, 2 \mathrm{mM}$ EDTA, 1 mM EGTA, $50 \mathrm{mM} \mathrm{NaF}, 4 \mu \mathrm{g} / \mathrm{mL}$ leupeptin, $0.1 \mathrm{mM} \mathrm{Na}_{3} \mathrm{VO}_{4}, 1 \mathrm{mM}$ PMSF, $1 \times$ Protease Inhibitors Complete EDTA free [Roche]), and pelleted into $\mathrm{N}_{2}(\mathrm{l})$. Ten grams of cells were then disrupted by cryo-grinding with a Retsch MM $400(3 \times 3 \mathrm{~min}$ at $30 \mathrm{~Hz})$. Sixteen milliliters of lysis buffer was added to the powder and stirred for ca. $15 \mathrm{~min}$ in the cold room. The salt concentration was now adjusted, if required. The lysate was spun for $25 \mathrm{~min}$ at $12,000 \mathrm{rpm}\left(4^{\circ} \mathrm{C}\right)$. The supernatant was then incubated with 200 $\mu \mathrm{L}$ of IgG-Sepharose for $2 \mathrm{~h}$ at $4^{\circ} \mathrm{C}$ on a rocker. The beads were transferred to a column and washed three times with $10 \mathrm{~mL}$ of washing buffer (10 mM Tris- $\mathrm{HCl}[\mathrm{pH} 8.0], 150 \mathrm{mM} \mathrm{NaCl}, 0.1 \%$ $\mathrm{NP}-40)$ and once with TEV-cleavage buffer (10 mM Tris- $\mathrm{HCl}[\mathrm{pH}$ 8.0], $150 \mathrm{mM}$ KOAc, 0.1\% NP-40, $0.5 \mathrm{mM}$ EDTA, 1 mM DTT). The TEV-cleavage reaction was performed using $50 \mathrm{U}$ of acTEV (Invitrogen) in $1 \mathrm{~mL}$ of TEV-cleavage buffer for $1 \mathrm{~h}$ at $25^{\circ} \mathrm{C}$. Where indicated, the RNase I (Ambion) treatment was subsequently performed for $1 \mathrm{~h}$ at RT using $500 \mathrm{U}$. The eluate was then transferred to a new column and the old column was washed out with $0.5 \mathrm{~mL}$ of TEV-c buffer. Three milliliters of Calmodulinbinding buffer (CAM-B: $10 \mathrm{mM}$ Tris- $\mathrm{HCl}[\mathrm{pH} 8.0], 150 \mathrm{mM}$ $\mathrm{NaCl}, 1 \mathrm{mM} \mathrm{Mg}[\mathrm{OAc}]_{2}, 1 \mathrm{mM}$ imidazole, $2 \mathrm{mM} \mathrm{CaCl}_{2}, 10 \mathrm{mM}$ $\beta$-mercaptoethanol), $4.5 \mu \mathrm{L}$ of $1 \mathrm{M} \mathrm{CaCl}_{2}$, and $150 \mu \mathrm{L}$ of Calmodulin-Sepharose were added and incubated for $1 \mathrm{~h}$ at $4^{\circ} \mathrm{C}$ on a rocker. The beads were washed twice with $1.5 \mathrm{~mL}$ CAM-B (0.1\% NP-40) and once with $1.5 \mathrm{~mL}$ CAM-B (0.02\% NP-40). The purified proteins were eluted from the column using $1 \mathrm{~mL}$ of
CAM-E (=CAM-B, but replacing the $\mathrm{CaCl}_{2}$ with 10 mM EGTA). The eluate was split into two aliquots and each of them was TCAprecipitated. One pellet was resuspended in $1 \times$ LDS sample buffer and run on a $4 \%-12 \%$ NuPAGE gel (Invitrogen) using MOPS buffer followed by silver- or Coomassie-staining (Colloidal Blue Staining kit, Invitrogen). The other pellet was used for mass spectrometric analysis.

\section{Sucrose density gradient centrifugation}

The lysate was prepared as for the TAP purifications ( $0.5 \mathrm{~g}$ of cryo ground powder). After the high-speed spin, $300 \mu \mathrm{L}$ of the lysate was loaded onto a $18 \%-54 \%$ sucrose gradient (buffered with $20 \mathrm{mM}$ Tris-HCl [pH 7.5], $150 \mathrm{mM} \mathrm{KCl,} 1 \mathrm{mM}$ DTT, $1 \mathrm{mM}$ PMSF). Complexes were separated by ultracentrifugation for $18 \mathrm{~h}$ at $39,000 \mathrm{rpm}\left(4^{\circ} \mathrm{C}\right)$ with an SW40 rotor (Beckman). The gradient was unloaded from the bottom with $70 \%$ sucrose. Twelve fractions of $1 \mathrm{~mL}$ were taken using a fraction collector while reading the absorbance at $254 \mathrm{~nm}$ with a UV reader. Twenty-eight microliters of the fractions was separated on a $4 \%-12 \%$ NuPAGE gel, blotted to nitrocellulose $(1.5 \mathrm{~h}$ at $200 \mathrm{~mA})$, and the proteins of interest were detected using the ECL system. Antibodies were used at 1:10,000 ( $\alpha$-PAP, Sigma), 1:20 ( $\alpha$-HA, FMI monoclonal antibody), 1:3000 ( $\alpha$-Mtr4, custom polyclonal, Eurogentec).

For the ribosome fractionation, $100 \mu \mathrm{g} / \mathrm{mL}$ cycloheximide or $1 \mathrm{mM}$ puromycin was added to $250 \mathrm{~mL}$ of an exponentially growing $S$. pombe culture. The culture was incubated for another $10 \mathrm{~min}$ at $30^{\circ} \mathrm{C}$ and then pelleted. The cells were washed once and then resuspended in $0.5 \mathrm{~mL}$ of lysis buffer $(20 \mathrm{mM}$ Tris- $\mathrm{HCl}[\mathrm{pH}$ 7.5], $150 \mathrm{mM} \mathrm{KCl}, 5 \mathrm{mM} \mathrm{MgCl}_{2}, 1 \mathrm{mM}$ EGTA, $1 \mathrm{mM}$ PMSF, $1 \times$ Protease Inhibitors Complete EDTA-free [Roche], $100 \mu \mathrm{g} / \mathrm{mL}$ Cycloheximide or $1 \mathrm{mM}$ puromycin). For the puromycin treated sample, the $\mathrm{MgCl}_{2}$ concentration in all buffers was reduced to $1 \mathrm{mM}$. One milliliter of glass beads was added and the cells were disrupted using a bead-beater $(4 \times 30 \mathrm{sec})$. The lysate was spun for $15 \mathrm{~min}$ at $16,000 \mathrm{rpm}, 4^{\circ} \mathrm{C}$, and then $300 \mu \mathrm{L}$ of the supernatant was loaded onto a $10 \%-50 \%$ gradient, which was prepared as described above. The ultracentrifugation was carried out for $15 \mathrm{~h}$ at $27,000 \mathrm{rpm}$ in a SW40 rotor (Beckman). In this case, 24 fractions of $0.5 \mathrm{~mL}$ were collected as described above.

\section{Mass spectrometry}

SDS-PAGE separated proteins and TCA-precipitated and acetonewashed protein pellets were reduced with TCEP, alkylated with iodoacetamide, and digested with trypsin. The generated peptides were analyzed by NanoLC-MSMS on a 4000Q Trap as described (Supplemental Table S1; Hess et al. 2008). The proteins were identified with Mascot searching Uniprot 15.6 (Perkins et al. 1999).

\section{S. pombe tiling arrays and data analysis}

RNA was isolated from cells collected at $\mathrm{OD}_{600}=0.5$ using the hot phenol method (Leeds et al. 1991). The isolated RNA was processed according to the GeneChip Whole Transcript (WT) Double-Stranded Target Assay Manual from Affymetrix using the GeneChip S. pombe Tiling 1.0FR. For analysis of the tiling arrays, an R-based script was used, which is available upon request. We used the genome and annotations from the $S$. pombe Genome 
Project (http://www.sanger.ac.uk/Projects/S_pombe/). The oligos from the Affymetrix .BPMAP file were remapped using bowtie and the .GFF file was used to map them to the genes. The resulting .CDF file is available upon request. The expression data from cid14A was compared to ChIP-on-chip data for H3K9me2 (Cam et al. 2005) by plotting, for each annotated element, enrichment/input for the ChIP data against cid14A/wt for the expression data. The average of two biological replicates was taken for each data set.

\section{SUPPLEMENTAL MATERIAL}

Supplemental material can be found at http://www.rnajournal.org. Tiling array data are reposited at the Gene Expression Omnibus (http://www.ncbi.nlm.nih.gov/geo/), accession number GSE20905.

\section{ACKNOWLEDGMENTS}

We thank Nicolas Thomä and the members of the Bühler lab for helpful discussions and comments on the manuscript. We thank Ben Hurschler and the Grosshans laboratory for technical help with sucrose gradients, and Yukiko Shimada and Nathalie Laschet for technical support. This work was supported by the Swiss National Science Foundation (SNF) and the Novartis Research Foundation.

Received December 17, 2009; accepted February 19, 2010.

\section{REFERENCES}

Bahler J, Wu JQ, Longtine MS, Shah NG, McKenzie A III, Steever AB, Wach A, Philippsen P, Pringle JR. 1998. Heterologous modules for efficient and versatile PCR-based gene targeting in Schizosaccharomyces pombe. Yeast 14: 943-951.

Bühler M. 2009. RNA turnover and chromatin-dependent gene silencing. Chromosoma 118: 141-151.

Bühler M, Haas W, Gygi SP, Moazed D. 2007. RNAi-dependent and -independent RNA turnover mechanisms contribute to heterochromatic gene silencing. Cell 129: 707-721.

Bühler M, Spies N, Bartel DP, Moazed D. 2008. TRAMP-mediated RNA surveillance prevents spurious entry of RNAs into the Schizosaccharomyces pombe siRNA pathway. Nat Struct Mol Biol 15: $1015-1023$.
Cam HP, Sugiyama T, Chen ES, Chen X, FitzGerald PC, Grewal SI. 2005. Comprehensive analysis of heterochromatin- and RNAimediated epigenetic control of the fission yeast genome. Nat Genet 37: 809-819.

Hess D, Keusch JJ, Oberstein SAL, Hennekam RCM, Hofsteenge J. 2008. Peters Plus syndrome is a new congenital disorder of glycosylation and involves defective $O$-glycosylation of thrombospondin type 1 repeats. J Biol Chem 283: 7354-7360.

Houseley J, Tollervey D. 2006. Yeast Trf5p is a nuclear poly(A) polymerase. EMBO Rep 7: 205-211.

Kwak JE, Wickens M. 2007. A family of poly(U) polymerases. RNA 13: $860-867$.

LaCava J, Houseley J, Saveanu C, Petfalski E, Thompson E, Jacquier A, Tollervey D. 2005. RNA degradation by the exosome is promoted by a nuclear polyadenylation complex. Cell 121: 713-724.

Leeds P, Peltz SW, Jacobson A, Culbertson MR. 1991. The product of the yeast UPF1 gene is required for rapid turnover of mRNAs containing a premature translational termination codon. Genes Dev 5: 2303-2314.

Mitchell P, Tollervey D. 2000. Musing on the structural organization of the exosome complex. Nat Struct Biol 7: 843-846.

Mitchell P, Petfalski E, Shevchenko A, Mann M, Tollervey D. 1997. The exosome: A conserved eukaryotic RNA processing complex containing multiple $3^{\prime} \rightarrow 5^{\prime}$ exoribonucleases. Cell 91: 457-466.

Perkins DN, Pappin DJ, Creasy DM, Cottrell JS. 1999. Probabilitybased protein identification by searching sequence databases using mass spectrometry data. Electrophoresis 20: 3551-3567.

Rissland OS, Mikulasova A, Norbury CJ. 2007. Efficient RNA polyuridylation by noncanonical poly(A) polymerases. Mol Cell Biol 27: 3612-3624.

Stevenson AL, Norbury CJ. 2006. The Cid1 family of noncanonical poly(A) polymerases. Yeast 23: 991-1000.

Vanacova S, Wolf J, Martin G, Blank D, Dettwiler S, Friedlein A, Langen H, Keith G, Keller W. 2005. A new yeast poly(A) polymerase complex involved in RNA quality control. PLoS Biol 3: e189. doi: 10.1371/journal.pbio.0030189.

Wang SW, Stevenson AL, Kearsey SE, Watt S, Bahler J. 2008. Global role for polyadenylation-assisted nuclear RNA degradation in posttranscriptional gene silencing. Mol Cell Biol 28: 656-665.

Win TZ, Draper S, Read RL, Pearce J, Norbury CJ, Wang SW. 2006. Requirement of fission yeast Cid14 in polyadenylation of rRNAs. Mol Cell Biol 26: 1710-1721.

Wyers F, Rougemaille M, Badis G, Rousselle JC, Dufour ME, Boulay J, Regnault B, Devaux F, Namane A, Seraphin B, et al. 2005. Cryptic pol II transcripts are degraded by a nuclear quality control pathway involving a new poly(A) polymerase. Cell 121: $725-737$. 

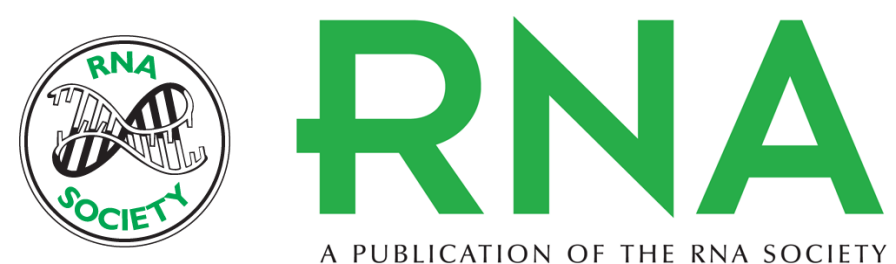

A PUBLICATION OF THE RNA SOCIETY

\section{Proteomic and functional analysis of the noncanonical poly(A) polymerase Cid14}

Claudia Keller, Katrina Woolcock, Daniel Hess, et al.

RNA 2010 16: 1124-1129 originally published online April 19, 2010

Access the most recent version at doi:10.1261/rna.2053710

\section{Supplemental http://rnajournal.cshlp.org/content/suppl/2010/04/12/rna.2053710.DC1 \\ Material}

References This article cites 19 articles, 6 of which can be accessed free at:

http://rnajournal.cshlp.org/content/16/6/1124.full.html\#ref-list-1

\section{License}

Email Alerting Receive free email alerts when new articles cite this article - sign up in the box at the Service top right corner of the article or click here. 